\title{
TESTE DE ARQUÉTIPOS
}

\author{
Archetypes Testing
}

Alex Mateus Porn'; Leticia Mara Peres²

Resumo O aumento da interoperabilidade entre sistemas de informação em saúde é possível utilizando o padrão de modelagem openEHR. Para verificar a corretude de arquétipos nesse padrão, este trabalho propõe-se convertê-los em ontologias OWL e realizar o teste de mutação. Assim, pretende-se revelar defeitos na modelagem do domínio antes de sua integração com outros sistemas.

Palavras-chave: Cuidado de Saúde Pervasivo, Computação Ubíqua, openEHR, Arquétipos, Linguagem Específica de Domínio

Abstract Increasing interoperability among health information systems is possible using openEHR standard modeling. In this work it is proposed to convert this pattern archetypes into OWL ontologies and perform mutation testing, to verify their correctness. Thus, we intend to reveal defects in the modeling domain before its integration with other systems.

Keywords: Archetypes, ADL, ontologies, OWL, mutation testing. 


\section{Introdução}

Visando a eliminar problemas de interoperabilidade entre sistemas de informação em saúde, a modelagem multinível openEHR' propõe o desenvolvimento de sistemas em dois níveis: Modelo de Referência e Modelo de Arquétipos ${ }^{[1]}$.

Arquétipos no padrão openEHR são definidos em ADL, linguagem que permite a estruturação da informação, mas dificulta a análise semântica do conteúdo representado. A corretude do arquétipo também não é uma atividade facilmente automatizável devido àquela característica da linguagem. Processos de troca e transformação de dados entre sistemas tornam-se mais difíceis do que utilizar modelos orientados à semântica, como ontologias.

A representação de arquétipos $A D L$ em OWL tornase uma alternativa ao problema, pois ontologias são a base do desenvolvimento da Web Semântica³.

Como não existe apenas uma forma correta de modelar um domínio específico do conhecimento, defeitos podem ser cometidos ao modelar arquétipos e ontologias. Esses problemas estão relacionados a características próprias da linguagem e geralmente confundem modeladores ${ }^{2}$.

Assim, motivam-se métodos de teste que validem os modelos clínicos representados em ADL.

Este trabalho propõe traduzir arquétipos ADL para ontologias $\mathrm{OWL}$, para realizar testes de validação semântica de arquétipos openEHR.

\section{Materiais e Métodos}

Foram analisados 5 arquétipos do CKM5, o repositório de arquétipos openEHR, sendo um para cada tipo de
Entry. O objetivo desta análise foi verificar a corretude dos arquétipos.

Esses arquétipos foram convertidos para OWL, através de um algoritmo de mapeamento de ADL para $\mathrm{OWL}^{3}$, sendo o processo realizado com a ferramenta Protégét, de criação e edição de ontologias.

Para a realização dos testes, aplicou-se o critério Análise de Mutantes ${ }^{8}$, e foram criados 12 operadores de mutação para OWL. Estes operadores geram mutantes, que são as novas estruturas com os defeitos simulados.

Usou-se a ferramenta Protégé para gerar os mutantes e interpretar consultas escritas em $D L$ Query ${ }^{6}$, que são os dados de entrada do teste.

\section{Resultados}

\begin{tabular}{|l|l|}
\hline $\begin{array}{l}\text { Operadores } \\
\text { de Mutação }\end{array}$ & Descrição \\
\hline CUC & $\begin{array}{l}\text { Uma classe sobe um nível na hierar- } \\
\text { quia e suas subclasses acompanham } \\
\text { a mudança, ficando associadas a ela. }\end{array}$ \\
\hline CUP & $\begin{array}{l}\text { Uma classe sobe um nível na hierar- } \\
\text { quia e suas subclasses não acompan- } \\
\text { ham esta mudança, permanecendo } \\
\text { associadas à superclasse original. }\end{array}$ \\
\hline CDD & $\begin{array}{l}\text { Cria uma definição de disjunção en- } \\
\text { tre classes, para todas as subclasses } \\
\text { de uma determinada classe. }\end{array}$ \\
\hline CDUO & $\begin{array}{l}\text { Remove uma das classes da definição } \\
\text { de disjunção de um conjunto de três } \\
\text { ou mais classes. }\end{array}$ \\
\hline CDUA & $\begin{array}{l}\text { Elimina completamente uma definição } \\
\text { de disjunção entre classes. }\end{array}$ \\
\hline CEU & $\begin{array}{l}\text { Remove uma definição de equivalên- } \\
\text { cia de uma classe. }\end{array}$ \\
\hline CEUA & $\begin{array}{l}\text { Altera uma definição de equivalência } \\
\text { definida por uma expressão lógica } \\
\text { (A and B), para (A) ou (B). }\end{array}$ \\
\hline
\end{tabular}

[1] Modela conceitos do domínio clínico a partir do modelo de referência.

[2] O ideal é que o escore de mutação seja o mais alto possível. Assim, foi calculado diretamente como a razão entre o número de mutantes mortos e gerados, sendo desconsiderados mutantes equivalentes, objetivando manter os resultados sem a intervenção do usuário. 


\begin{tabular}{|l|l|}
\hline CEUO & $\begin{array}{l}\text { Altera uma definição de equivalência } \\
\text { definida por uma expressão lógica } \\
\text { (A or B), para (A) ou (B). }\end{array}$ \\
\hline PDD & $\begin{array}{l}\text { Troca uma definição de domínio de } \\
\text { uma propriedade por uma subclasse } \\
\text { da classe originalmente definida } \\
\text { como sendo este domínio. }\end{array}$ \\
\hline PRD & $\begin{array}{l}\text { Troca uma definição de intervalo de } \\
\text { uma propriedade por uma subclasse } \\
\text { da classe originalmente definida como } \\
\text { sendo limitadora deste intervalo. }\end{array}$ \\
\hline ACOTA & $\begin{array}{l}\text { Altera a definição de equivalência } \\
\text { definida por uma expressão lógica } \\
\text { (A or B), para (A and B). }\end{array}$ \\
\hline ACSTA & $\begin{array}{l}\text { Altera uma definição de equivalên- } \\
\text { cia definida por uma expressão } \\
\text { lógica utilizando a restrição de valor } \\
\text { existencial SomeValues, substituíndo } \\
\text { pela restrição universal AllValues. }\end{array}$ \\
\hline
\end{tabular}

Quadro 1: Operadores de Mutação

Após a geração dos mutantes e da execução dos dados de teste para revelar o defeito inserido pelo operador de mutação (dizendo-se que o mutante está "morto"), foram obtidos os resultados da Tabela 1, para um arquétipo do tipoEvaluation.

\begin{tabular}{|l|l|l|l|l|}
\hline \multirow{2}{*}{$\begin{array}{l}\text { Operadores } \\
\text { de Mutação }\end{array}$} & \multicolumn{2}{|c|}{ Número de Mutantes } & Escore de \\
\cline { 2 - 4 } & Gerado & Morto & Vivo & \\
\hline Mutação'
\end{tabular}

Tabela 1: Mutantes gerados para cada operador de mutação.
Ao contrário dos dois operadores que não obtiveram escore de mutação (0\%), por necessitarem de indivíduos instanciados para produzirem efeitos, os demais apresentaram resultados altamente satisfatórios.

O operador CUC, que altera a estrutura hierárquica da ontologia, mostra possíveis irregularidades de desenvolvimento (Figura 1).
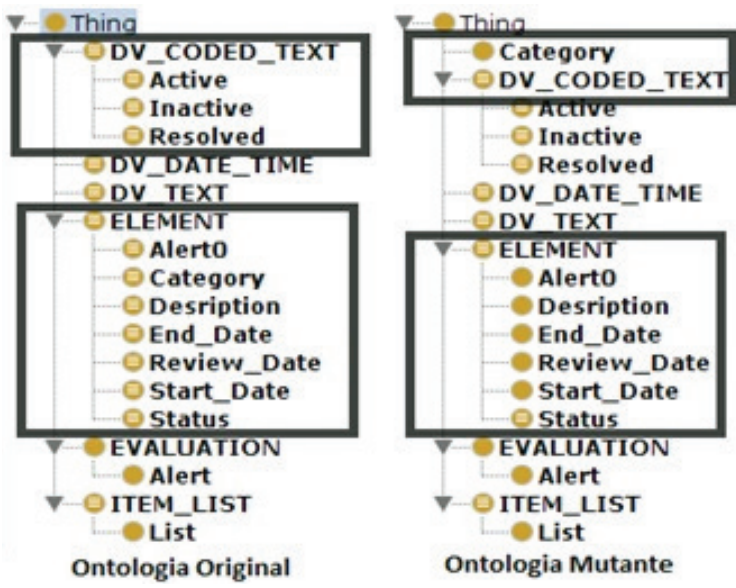

Figura 1: Modelo de arquétipo OWL com aplicação do operador CUC.

Devido à representação semântica do modelo através de axiomas, conforme o arquétipo $A D L$, ambas as versões desta figura são instanciadas similarmente em 07 dos 12 mutantes gerados, caracterizando-os como equivalentes (Figura 2). Três mutantes mortos com este operador possuem definições de equivalência, podendo caracterizar definições incorretas de axiomas, invalidando a hipótese do operador ser aplicado somente em classes que não possuam definição.
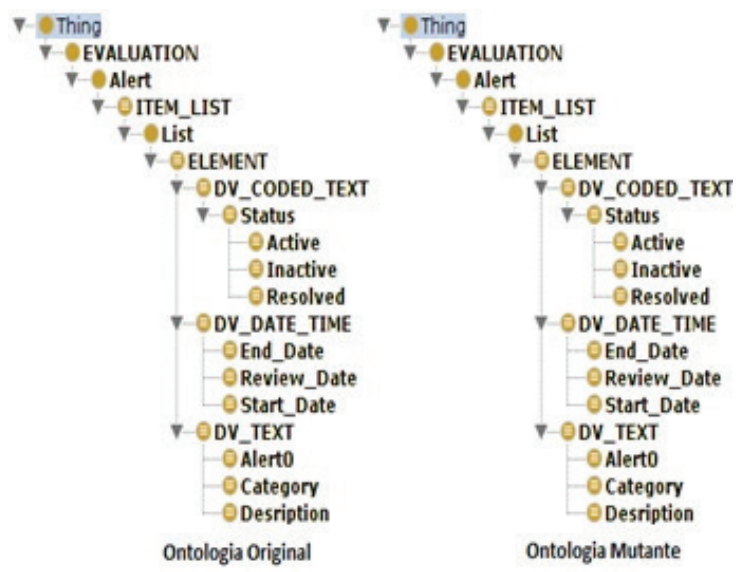

Figura 2: Representação de mutante vivo com o operador CUC. 
Para o operador ACOTA, dos 16 mutantes gerados, obteve-se $100 \%$ de escore de mutação, i.e., de adequação nos casos de teste.

O mesmo ocorre para o operador ACSTA. A adequação total desses casos de teste significa que o operador ACOTA revela falhas com os operadores AND e OR, e que o operador ACSTA revela a aplicação incorreta em axiomas dos operadores de restrição universal e existencial.

Nota-se também a grande quantidade de mutantes e o alto escore de mutação dos operadores, permitindo validar e adequar o modelo proposto de mutação.

Alguns dos operadores utilizados revelaram defeitos que ocorrem no desenvolvimento ou conversão de arquétipos, de modo que não apresentam falhas na execução, mas retornam resultados insatisfatórios.

Com base nos operadores e testes aplicados, percebe-se a utilidade dos testes para arquétipos.

\section{Conclusão}

No desenvolvimento de arquétipos e ontologias cometem-se vários erros, que podem vir a gerar defeitos na utilização de sistemas, conforme descrito na literatura ${ }^{3}$.
O teste de mutação permite a geração de dados de teste para a identificação de defeitos que não seriam revelados se o teste não fosse executado. Os resultados desse trabalho indicam que o teste de mutação é um excelente critério de teste, adequado para a validação de corretude de arquétipos e ontologias.

Dado que operadores de mutação já foram definidos, mais experiências práticas desse tipo devem ser conduzidas para a validação dessas estruturas, antes de sua implantação em sistemas reais.

\section{Referências}

1. Beale T, Kalra D, Heard S, Lloyd D. The openEHR Reference Model: EHR Information Model, agosto de 2008.

2. Poveda-Villalón M, Suárez-Figueroa MC, Gómez-Pérez A. A Double Classification of Common Pitfalls in Ontologies. Workshop on Ontology Quality (OntoQual 2010), Colocated with EKAW 2010, outubro de 2010.

3. Jepsen TC. Just What Is an Ontology, Anyway? IT Professional, 11(5):22-27, 2009.

4. PROTÉGÉ 4.3. Software para ontologias. Disponível em: http://protege.stanford. edu/download/registered.html, acesso em: 10 dez. 2013.

5. openEHR. Repositório de arquétipos ADL. Disponível em: http://www.openehr.org/ ckm/, acesso em: 10 dez. 2013.

6. DL Query. DL Query Plugin. Disponível em: http://protegewiki.stanford.edu/wiki/ DLQueryTab, acesso em 10 dez, 2013.

7. Bechhofer S, Harmelen F, Hendler J, Horrocks I, McGuinness DL, Schneider PFP, Stein LA. OWL Web Ontology Language Reference. w3c, fevereiro de 2004.

8. DeMillo RA, Lipton RJ, Sayward FG. Hints on Test Data Selection: Help for the Practicing Programmer. Computer, 11(4):34\{41, abril de 1978. 